\title{
First estimates of influenza vaccine effectiveness among severe influenza cases, France, 2011/12
}

I Bonmarin (i.bonmarin@invs.sante.fr) ${ }^{1}$, E Belchior $^{1}$, Y Le Strat $^{1}$, D Lévy-Bruhl $^{1}$

1. Département des maladies infectieuses, Institut de veille sanitaire, Saint-Maurice, France

Citation style for this article:

Bonmarin I, Belchior E, Le Strat Y, Lévy-Bruhl D. First estimates of influenza vaccine effectiveness among severe influenza cases, France, 2011/12. Euro Surveill.

2012;17(18):pii=20163. Available online: http://www.eurosurveillance.org/ViewArticle.aspx?Articleld=20163

Article submitted on 30 March 2012/ published on 3 May 2012

Following a suspected virus-vaccine mismatch, the screening method was used to estimate in almost real time the influenza vaccine effectiveness (VE) against severe cases in high-risk individuals. Data on vaccination status were provided by the influenza severe surveillance system and data on vaccination coverage by the National Social Security Scheme. The analysis showed a decline of the vaccine effectiveness in 2011/12 (VE: 30\% (95\% Cl: 22-39)) compared to 2010/11 (VE: $53 \%$ (95\% Cl: 40-67)).

\section{Introduction}

In France, the 2011/12 influenza epidemic started in week 5 of 2012 (30 January-5 February 2012), peaked in week 8 of 2012 (20-26 February 2012), and was dominated by the influenza $\mathrm{A}\left(\mathrm{H}_{3} \mathrm{~N}_{2}\right)$ virus. In week 6 of 2012, the National Reference Laboratory for influenza reported a possible mismatch between the $A\left(\mathrm{H}_{3} \mathrm{~N}_{2}\right)$ vaccine strain and the circulating strains [1]. We used the available surveillance data in France in order to assess in real time the influenza trivalent vaccine effectiveness (VE) against severe cases in high-risk individuals targeted for vaccination (see below).

\section{Methods}

In France, a nationwide exhaustive hospital-based surveillance of severe influenza cases has been implemented since the 2009 pandemic [2]. Clinicians are requested to report to the French Institute for Public Health Surveillance (Institut de Veille Sanitaire - InVS) all probable and confirmed influenza cases admitted to intensive care unit (ICU) through a standardised notification form. Confirmed cases are patients positive for influenza by RT-PCR performed on a nasal swab. Age is recorded as a quantitative variable and vaccine status and risk factors targeted by the vaccination as dichotomous variables. Information on the type of underlying medical conditions and on the vaccination date is not collected.

The French influenza vaccination strategy targets individuals aged 65 years old or older and persons below 65 years of age with specific chronic underlying conditions (such as chronic respiratory diseases, diabetes), pregnant women and obese persons [3]. Each autumn, the National Health Insurance Scheme for Employees (Caisse nationale de l'assurance maladie des travailleurs salariés - CNAMTS), the main social security scheme, covering about $85 \%$ of the French population, sends an individual vaccination voucher to the population targeted by the influenza vaccination strategy. The voucher allows the recipients to get the vaccine from the pharmacist and its administration by the general practitioner (GP) free of charge. The pharmacist issuing the vaccine returns the voucher to the CNAMTS in order to get refunded. In 2011, pregnant women and obese persons did not receive a voucher if they had no chronic co-morbidities. During the vaccination campaign, the vaccine uptake, based on the voucher return rates, is monitored by CNAMTS which provides InVS with provisional weekly estimates for the population targeted by the vaccination (obese persons and pregnant women excluded), stratified into three age groups: under 65 years, between 65 and 69 years and 70 years old or older.

We estimated the VE against laboratory-confirmed influenza ICU cases through the screening method [4]. The proportion of vaccinated cases (PCV) was provided by the ICU influenza surveillance. A case was defined as an influenza laboratory-confirmed patient with a known vaccination status. The proportions of the population vaccinated (PPV) in the three categories (under 65 years, between 65 and 69 years and 70 years old or older) were provided by the voucher return rates. The data were adjusted on age and sex as a previous analysis based on the same source of data has shown that vaccine coverage was lower among women [5]. VE was calculated using the formula shown and based on a log-linear model, as proposed by Farrington [6].

$$
V E=\frac{P P V-P C V}{P P V(1-P C V)}
$$


The $95 \%$ confidence intervals $(\mathrm{Cl})$ were estimated through the delta method. Pregnant women and obese persons were excluded from the analysis.

We compared the VE in the $2011 / 12$ season with the estimate for the 2010-11 season obtained through the same method and source of data.

\section{Results}

On 31 January 2012, which represents the end date of the vaccination campaign, the provisional influenza vaccination uptakes were $40 \%$ in the population under 65 years targeted by the vaccination, $41 \%$ in the $65-69$ age group and $60 \%$ in the age group of individuals aged 70 years old or older, in plateau since mid-December 2011. These results are in line with the 2010/11 CNAMTS final consolidated data.

As of 18 April 2012, 308 severe influenza cases had been notified by the ICU clinicians. Of these, 294 were laboratory-confirmed and are described in the table.

The virus subtype was known for 119 in 288 influenza $A$ cases and $A\left(H_{3} N_{2}\right)$ virus accounted for $90 \%(n=107)$ of them.

Among the 234 severe influenza cases confirmed in high-risk individuals, the vaccination status was available for 176 cases: 67 under 65 years old, 20 aged between 65-69 years and 89 aged 70 years or more. The proportions of vaccinated cases were $30 \%, 30 \%$ and $43 \%$, respectively. This corresponds to a trivalent VE of $30 \%$ (95\% Cl: 22-39).

In $2010 / 11$, the VE for high-risk individuals was estimated from 239 confirmed severe cases with a known vaccine status and it was $53 \%(95 \% \mathrm{Cl}: 40-67)$.

\section{Conclusions}

Our study shows a significant decrease of the trivalent influenza VE against severe influenza cases in high-risk patients in $2011 / 12$, as compared to the previous season. These data are consistent with the $\mathrm{A}\left(\mathrm{H}_{3} \mathrm{~N}_{2}\right)$ antigenic variations from the vaccine strain observed by the National Reference Laboratory for influenza. They explain, at least partially, the particularly high number of acute respiratory infections clusters notified in nursing homes in France this season (884 [7] as compared to 153 last year [8]). They also support the World Health Organization's (WHO) recommendation of changing the $A\left(\mathrm{H}_{3} \mathrm{~N}_{2}\right)$ strain to be included in the vaccine for the next season [9]. However, the VE point estimate is lower than the recent estimates yielded by studies performed in general practice sentinel networks (adjusted VE against any type: $55 \%$ (95\% Cl: $3-79)$ in Spain and adjusted VE against $\mathrm{A}\left(\mathrm{H}_{3} \mathrm{~N}_{2}\right): 43 \%(95 \% \mathrm{Cl}:-0.4$ to $67.7)$ in the European project, Influenza - Monitoring Vaccine Effectiveness (I-MOVE) [10,11]. Although VE is expected to be higher for the prevention of the most severe influenza outcomes, this result may illustrate the fact that the high-risk individuals presenting with severe influenza requiring ICU may be, on average, more immunocompromised and may not respond well to the vaccine as those in general practices for instance. Consolidated data with a narrower interval are expected from the European project, I-MOVE with a comparison between the vaccine efficacy in GP sentinel networks this season and the previous season [12].

The study has however several limitations. Firstly, vaccination dates of the patients were not available. As the vast majority of cases occurred after January 2012 and the vaccine uptake has reached a plateau since December 2011, we assumed that patients were vaccinated more than two weeks before the onset of the disease. Secondly, even though the vaccination coverage was calculated in the population of high-risk individuals, as was the proportion of vaccinated cases, it was not possible to investigate the type and severity of the underlying conditions. We could only stratify the analysis according to sex and age. We assumed that if confounding did occur, it should have affected similarly the results during the two seasons. Thirdly, the vaccine status was missing for $25 \%(n=58 / 234)$ of the high-risk patients. We think that missing data are more likely to occur among unvaccinated patients leading to an underestimation of the VE. In 2010-11, information on vaccination status was unavailable for $34 \%$ of the cases. Therefore, the substantial decrease of VE between the two seasons is likely to be real and potentially underestimated. Fourthly, the vaccine coverage data we used are provisional. However, the experience accumulated over the years has shown very little variations between provisional estimates available in March and the definitive figures. It is important to note that coverage data from the other Social Security Schemes (covering about $15 \%$ of the population) are usually very close to data from CNAMTS (personal communication, CNAMTS, January 2012).

The study found a decline of the VE in the context of a mismatch of the vaccine strains with circulating viruses

TABLE

Severe laboratory-confirmed cases of influenza, France, 2011/12 (n=294)

\begin{tabular}{|l|c|c|}
\hline Description & Results & Number of cases for whom the information is available \\
\hline Male to female sex ratio & $1.2: 1$ & 292 \\
\hline Mean age (years) & $59(95 \% \mathrm{Cl}: 56-61)$ & 290 \\
\hline Number of patients with risk factors & 234 & 290 \\
\hline Number of vaccinated patients & 65 & 222 \\
\hline
\end{tabular}


and showed the usefulness of the screening method for almost real-time monitoring of VE during the influenza season.

\section{Acknowledgements}

We thank for their data all the intensive care units (ICU) clinicians and their learned societies the Société de Réanimation de Langue Française (SRLF), the Groupe Francophone de Réanimation et Urgences Pédiatrique (GFRUP), the Société Française d'Anesthésie et de Réanimation(SFAR), all the Regional InVS offices (Cire), in charge of the ICU network managing as well as the CNAMTS for providing provisional vaccination coverage data.

\section{References}

1. Institut de Veille Sanitaire (InVS). Bulletin hebdomadaire grippe. Point au 15 février 2012. [Weekly Influenza Bulletin. Update: 15 February 2012]. Paris: InVS. French. Available from: http://www.invs.sante.fr/Dossiers-thematiques/Maladiesinfectieuses/Maladies-a-prevention-vaccinale/Grippe/ Grippe-generalites/Donnees-de-surveillance/2011-2012/ Bulletin-epidemiologique-grippe.-Point-au-15-fevrier-2012

2. Fuhrman C, Bonmarin I, Bitar D, Cardoso T, Duport N, Herida M, et al. Adult intensive-care patients with 2009 pandemic influenza $A\left(\mathrm{H}_{1} \mathrm{~N}_{1}\right)$ infection. Epidemiol Infect. 2011; 139(8):1202-9.

3. Haut Conseil de la Santé Publique. Avis relatif à l'actualisation de la stratégie vaccinale contre la grippe 2011-2012. Recommendations on the vaccination strategy against influenza 2011-2012]. 13 Jul 2011. Haut Conseil de la Santé Publique. French. Available from: http://www.hcsp.fr/docspdf/ avisrapports/hcspa20110713 actuastrategievaccingrippe.pdf

4. Orenstein WA, Bernier RH, Dondero TJ, Hinman AR, Marks JS, Bart KJ, et al. Field evaluation of vaccine efficacy. Bull World Health Organ. 1985;63(6):1055-68.

5. Tuppin P, Samson S, Weill A, Ricordeau P, Allemand H. [Influenza vaccination coverage in France in 2007-2008: contribution of vaccination refund data from the general health insurance scheme]. Med Mal Infect. 2009;39(10);780-8.

6. Farrington $C P$. Estimation of vaccine effectiveness using the screening method. Int J Epidemiol. 1993;22(4):742-6.

7. Institut de Veille Sanitaire (InVS). Bulletin hebdomadaire grippe. Point au 18 avril 2012. [Weekly Influenza Bulletin. Update: 18 April 2012]. Paris: InVS. French. Available from: http://www.invs.sante.fr/Dossiers-thematiques/Maladiesinfectieuses/Maladies-a-prevention-vaccinale/Grippe/ Grippe-generalites/Donnees-de-surveillance/2011-2012/ Bulletin-epidemiologique-grippe.-Point-au-18-avril-2012

8. Équipes de surveillance de la grippe. Surveillance épidémiologique et virologique de la grippe en France, saison 2010-2011. [Epidemiological and virological surveillance of influenza activity in France: season 2010-2011]. BEH. 2011:3738. 11 Oct 2011. French. Available from: http://www.invs. sante.fr/Publications-et-outils/BEH-Bulletin-epidemiologiquehebdomadaire/Derniers-numeros-et-archives/Archives/2011/ BEH-n-37-38-2011

9. World Health Organization (WHO). Recommended composition of influenza virus vaccines for use in the 2012-2013 northern hemisphere influenza season. Geneva: WHO. Feb 2012. Available from: http://www.who.int/influenza/vaccines/virus/ recommendations/201202_recommendation.pdf

10. Jiménez-Jorge S, de Mateo S, Pozo F, Casas I, García Cenoz M, Castilla J, et al. Early estimates of the effectiveness of the $2011 / 12$ influenza vaccine in the population targeted for vaccination in Spain, 25 December 2011 to 19 February 2012. Euro Surveill. 2012;17(12):pii=20129. Available from: http:// www.eurosurveillance.org/ViewArticle.aspx?Articleld =20129

11. Kissling E, Valenciano M, I-MOVE case-control studies team. Early estimates of seasonal influenza vaccine effectiveness in Europe among target groups for vaccination: results from the I-MOVE multicentre case-control study, 2011/12. Euro Surveill. 2012;17(15): pii=20146. Available from: http://www. eurosurveillance.org/ViewArticle.aspx?Articleld=20146

12. Kissling E, Valenciano M, Cohen JM, Oroszi B, Barret AS, Rizzo C, et al. I-MOVE multi-centre case control study 201011: overall and stratified estimates of influenza vaccine effectiveness in Europe. PLoS One. 2011;6(11):e27622. 